\title{
Hacia una concepción católica de la sociedad civil
}

\author{
Mauricio Correa \\ FACULTAD DE FILOSOFÍA \\ PONTIFICIA UNIVERSIDAD CATÓLICA DE CHILE \\ mcorrea9@uc.cl
}

Resumen: La expresión "sociedad civil" es utilizada de manera abundante en el magisterio social pontificio para significar la comunidad política o el Estado. Sin embargo, en documentos recientes de la Iglesia, así como en la enseñanza social de Benedicto XVI, la sociedad civil sirve para indicar una esfera social relativamente autónoma respecto del Estado y también del mercado. El autor advierte en este artículo sobre un posible problema en la justificación doctrinal de este nuevo significado de la sociedad civil y seguidamente expone algunos elementos que explican esta transformación semántica a la luz del magisterio de León XIII, Juan Pablo II y el mismo Benedicto XVI.

Palabras clave: Derecho de asociación, grupos intermedios, sociedad civil, Estado, mercado.

Abstract: The term "civil society" is used abundantly in the papal social teaching to mean the political community or the state. However, in recent documents of the Church and the social teaching of Benedict XVI, civil society serves to indicate a relatively autonomous social sphere from the state and the market. The author notes in this article about a possible problem in the doctrinal justification for this new meaning of civil society and then presents some elements that explain this semantic processing in the light of the teaching of Leo XIII, John Paul II and Benedict XVI himself.

Keywords: Right of association, intermediate groups, civil society, state, market. 


\section{PLANTEAMIENTO DE LA CUESTIÓN ${ }^{1}$}

La expresión sociedad civil es utilizada de manera abundante en la Doctrina Social de la Iglesia (en adelante DSI). Este dato es evidente al repasar los documentos sociales de los Sumos Pontífices que va de León XIII a Juan Pablo II $^{2}$. En este corpus social católico la perspectiva dominante ha consistido en identificar la societas civile o la communitatem civilem con la comunidad política o el Estado ${ }^{3}$. A la luz de este aspecto podemos afirmar con bastante seguridad que no existe en la DSI ningún uso de la expresión sociedad civil en su acepción contemporánea, esto es, como una esfera social relativamente autónoma respecto del Estado y también del mercado ${ }^{4}$. El giro más importante hacia este nuevo significado recién lo encontramos formulado explícitamente en la enseñanza del papa Bene-

1 Este artículo forma parte del Proyecto No1401/DPCC2012 financiado con el aporte de la Vicerrectoría de Investigación y la Dirección de Pastoral y Cultura Cristiana de la Pontificia Universidad Católica de Chile.

2 M. Correa Casanova (Ed.): Documentos del Magisterio Social Pontificio. De León XIII a Benedicto XVI (Publicaciones del Pontificio Seminario Mayor San Rafael, Valparaíso, 2013).

3 J. L. Gutiérrez García: Conceptos fundamentales en la Doctrina Social de la Iglesia (Centro de Estudios Sociales del Valle de los Caídos, Madrid 1971, vol. IV, voz: "Sociedad"), 282, sostiene: "El magisterio habla unas veces de la sociedad en general, sin adjetivos determinantes, y otras, de sociedad civil, aludiendo concretamente a la comunidad política». Según la explicación de Norberto Bobbio, "la expresión 'sociedad civil' [...] es utilizada normalmente para distinguir el ámbito de competencia del Estado o del poder civil del ámbito de competencia de la Iglesia o poder religioso en la contraposición sociedad civil/sociedad religiosa”, N. BobBio: Estado, Gobierno y Sociedad (FCE, México, 2006, 59). Véase también C. TAYLOR: Argumentos filosóficos (Paidós, Barcelona, 1997, 277).

4 Aunque en el ámbito de la Filosofía social y política no existe una definición en la que todos los especialistas estén de acuerdo, en general puede entenderse la sociedad civil como una esfera social situada en un espacio intermedio entre el Estado y el mercado, en la que los ciudadanos se organizan de manera voluntaria a través de una multiplicidad de grupos o asociaciones cuyo propósito consiste en alcanzar ciertos fines sociales, culturales, económicos, políticos o religiosos. Con matices evidentes, éste es el significado desarrollado ampliamente, entre otros, por J. Keane: Democracy and Civil Society (London and New York, Verso, 1988); A. Arato y J. Cohen: Civil Society and Political Theory (MIT Press, Cambridge Mass., 1992); M. WALzer: "The Civil Society Argument" (en R. Beiner: Theorizing Citizenship. State of New York Press, 1995, 153-174); J. Habermas: Facticidad y validez (Trotta, Madrid, 1998); C. TAYLOR: Argumentos filosóficos (Paidós, Barcelona, 1997); B. R. BARBER: A place for us: how to make society civil and democracy strong (Hill and Wang, New York, 1998); V. Pérez Díaz: La primacía de la sociedad civil (Alianza Editorial, Madrid, 
dicto XVI, especialmente en su Carta encíclica Caritas in veritate (29VI-2009), documento en el que la sociedad civil aparece utilizada en su nuevo sentido al menos en 10 ocasiones $^{5}$.

Sin duda, lo anterior constituye un avance crucial en los planteamientos de la DSI que nos permite sostener que la sociedad civil representa efectivamente una novedad que encierra un incalculable valor doctrinal y pastoral, especialmente si consideramos los actuales retos de la evangelización en el ámbito local y global cuyo proceso se realiza con independencia del Estado. Sin embargo, y a pesar de su novedad, creo que esta afirmación no se encuentra exenta de dificultades. La principal, a mi entender, se mueve en el orden de la justificación doctrinal que autoriza la utilización de la expresión en su nuevo significado. En efecto, ¿qué justifica que el papa Benedicto XVI use la expresión sociedad civil en su sentido contemporáneo en el marco de la DSI? En otras palabras -y dada la continuidad característica de la DSI-, ¿existe un fundamento doctrinal que justifique este nuevo significado de la sociedad civil como distinto de la comunidad política? A mi entender, la dificultad más grave para responder a estas preguntas se pone de manifiesto en la existencia de un vacío en la trayectoria histórica de la expresión, ya que, como he sostenido, la sociedad civil -al menos en su significado actual- nunca ha sido una "cuestión social" abordada por los sumos pontífices.

Lo dicho hasta aquí se comprueba fácilmente al examinar dos documentos recientes de la Iglesia en los cuales se define la sociedad civil en su nuevo sentido, esto es, como una esfera social relativamente autónoma.

Por un lado, y creo que por primera vez, la sociedad civil aparece formulada en su sentido actual en el documento Familia y derechos humanos de 1999, a cargo del Pontificio Consejo para la Familia (nn. 63-64). De acuerdo con este documento la sociedad civil representa una esfera social propia que se distingue de la sociedad política. En efecto, mientras esta última "tiene como razón de ser el ejercicio del poder, con el recurso, dado el caso, a la coerción"; la sociedad civil, en cambio, se constituye

1993); A. Etzioni: The New Golden Rule: Community and Morality in a Democratic Society (Basic Books, New York, 1996).

5 De todos modos, habría que decir que ese giro ya estaba presente de manera implícita en su primera Carta encíclica Deus caritas est (25-XII-2005), en concreto, cuando el Papa reflexiona sobre el sentido y el lugar propio de la actividad caritativa de la Iglesia. 
de cuerpos sociales intermedios que se valen de las afinidades, las alianzas voluntarias y las solidaridades naturales. Como tal, esta distinción cumple una doble finalidad: por una parte, viene a ilustrar el principio de subsidiaridad, en el sentido de que el Estado "no puede intervenir en los campos en los cuales la iniciativa de los particulares, de las comunidades y de las empresas, es suficiente"; asimismo, por otra, la distinción esclarece la rica realidad de la familia, la cual constituye "el núcleo central de la sociedad civil". Para justificar la distinción mencionada, así como el nuevo significado que se le atribuye a la sociedad civil, curiosamente no se hace referencia a ningún documento eclesial anterior, sino que se apela a la Declaración Universal de los Derechos Humanos de 1948, así como al francés Alexis de Tocqueville ${ }^{6}$.

Por otro lado, se vuelve a hablar de la sociedad civil en el Compendio de la Doctrina Social de la Iglesia del año 2004, a cargo del Pontificio Consejo Justicia y Paz. La exposición abarca las secciones 417 a 424, y aparece bajo el título "La comunidad política al servicio de la sociedad civil". En sentido estricto, la doctrina expuesta en el Compendio representa hasta ahora la única visión sistemática disponible sobre la concepción católica de la sociedad civil. Brevemente, se afirma que la sociedad civil no es un "mero apéndice o una variable de la comunidad política", sino que, al contrario, "tiene la preeminencia, ya que es precisamente la sociedad civil la que justifica la existencia de la comunidad política”. Dicho esto, se define la sociedad civil como "un conjunto de relaciones y de recursos, culturales y asociativos, relativamente autónomos del ámbito político y del económico"7. Su característica principal consiste en "su

6 Vid. A. De Tocqueville: De la démocratie en Amérique (ed. crítica de Eduardo Nolla, París, Vrin, 1990 [trad. cast. La democracia en América. Fondo de Cultura Económica, México, 1999]). La referencia a Tocqueville en el documento eclesial es muy relevante, ya que viene a explicitar una determinada opción dentro de las principales fuentes de la historia intelectual sobre la sociedad civil. Véase, entre muchos otros, L. Díez del Corral: El pensamiento politico de Tocqueville (Alianza, Madrid, 1989); J. M. Ros: Los dilemas de la democracia liberal. Sociedad Civil y democracia en Tocqueville (Crítica, Barcelona, 2001); H. E. S. Woldring: State and Civil Society in the Political Philosophy of Alexis de Tocqueville (Voluntas: International Journal of Voluntary and Nonprofit Organizations, vol. 9, N 4 (1998), 363-373); D. Villa: "Tocqueville and Civil Society" (en C. B. Welch, ed., The Cambridge Companion to Tocqueville, Cambridge University Press, 2006, 216-244).

7 Otra definición la encontramos en el n. 185: "Es éste el ámbito de la sociedad civil -nos dice-, entendida como el conjunto de las relaciones entre individuos y entre 
capacidad de iniciativa, orientada a favorecer una convivencia social más libre y justa, en la que los diversos grupos de ciudadanos se asocian y se movilizan para elaborar y expresar sus orientaciones, para hacer frente a sus necesidades fundamentales y para defender sus legítimos intereses". Seguidamente, se señala el principio de subsidiaridad para establecer el modo correcto en que se han de relacionar la comunidad política y la sociedad civil, así como también las expectativas éticas que pesan sobre esta última en el ámbito público.

Ahora bien, una primera observación crítica desde el punto de vista estructural, consiste en señalar que resulta francamente incomprensible que en el Compendio se siga tratando la sociedad civil como un capítulo de la comunidad política, siendo que lo más coherente hubiese sido concederle un capítulo aparte. De todos modos, lo más sorprendente es que para justificar su desarrollo no se hace ninguna mención del documento Familia y Derechos Humanos de 1999. Digo que esto sorprende si se tiene en cuenta que constituye el primer precedente en la materia. En todo caso, esto no significa que entre ambos documentos no se pueda establecer una continuidad doctrinal, o incluso una complementación. Respecto a las fuentes eclesiales a las que se hace referencia explícitamente para justificar la enseñanza sobre la sociedad civil podemos decir dos cosas: primero, que son muy escasas ${ }^{8}$, y segundo, que el uso resulta en varios casos incorrecto?.

Dicho lo anterior, en este artículo mi objetivo principal consiste en demostrar que el mencionado vacio en los fundamentos doctrinales ca-

sociedades intermedias, que se realizan en forma originaria y gracias a la 'subjetividad creativa del ciudadano'”.

8 Tales referencias son las siguientes: León XIII, Carta enc. Rerum novarum: Acta Leonis XIII, 11 (1891, sic) 134; Pío XI, Carta enc. Quadragesimo anno: AAS 23 (1931) 203; y Juan Pablo II, Carta enc. Centesimus annus, 49: AAS 83 (1991) 855. Las otras referencias son al Catecismo de la Iglesia Católica, números 1910, 1883-1885. Hay que llamar la atención, sin embargo, sobre el hecho de que ninguna de estas referencias se ofrece como fundamento directo de la distinción entre comunidad política y sociedad civil, como tampoco para la definición que se ofrece de esta última.

9 Por ejemplo, en el nº 417 del Compendio se cita León XIII, Carta enc. Rerum novarum: Acta Leonis XIII, 11 (1891, sic) 134, para apoyar la afirmación según la cual el fin establecido para la sociedad civil persigue el bien común. Sin embargo, si acudimos a la fuente, observamos que León XIII habla de la "sociedad civil" no en su sentido contemporáneo, sino como sinónimo del "Estado", el cual efectivamente tiene como fin el bien común. 
tólicos sobre la sociedad civil es solo aparente, y que, al contrario de la hipótesis anunciada, la noción de la sociedad civil en su acepción actual puede ser reconstruida con cierta continuidad y coherencia doctrinal siguiendo las enseñanzas papales que constituyen la fuente de la DSI. Por supuesto que exponer el recorrido completo de esta enseñanza sobrepasa los límites de este artículo. Por este motivo, voy a dividir mi exposición en tres partes considerando cronológicamente el magisterio social pontificio de León XIII, Juan Pablo II y Benedicto XVI. Según mi interpretación, cada uno de estos Papas ha ido formulado en su momento histórico particular los elementos esenciales que constituyen lo que podemos considerar como la concepción católica contemporánea de la sociedad civil.

\section{LEÓN XIII Y EL DERECHO DE ASOCIACIÓN}

Lo que podemos considerar como la noción católica de la sociedad civil se comienza a construir a partir de la rica tradición social de la Iglesia que se evidencia históricamente desde fines del siglo XIX, y que encuentra su primera fuente doctrinal en la Encíclica Rerum novarum (15-V-1891) de León XIII. En esta encíclica, efectivamente, el pontífice defiende el "derecho natural de asociación" estableciendo para ello la distinción entre dos tipos de sociedades, así como sus fines próximos y su modo de relación.

En cuanto a la distinción, el Papa habla de dos tipos de sociedades que responden, cada una a su modo, a un impulso natural del hombre que le mueve a juntar sus fuerzas con otros a causa de su propia insuficiencia. En palabras de León XIII:

La reconocida cortedad de las fuerzas humanas aconseja e impele al hombre a buscarse el apoyo de los demás [...] En virtud de esta propensión natural, el hombre, igual que es llevado a constituir la sociedad civil [entiéndase la comunidad política], busca la formación de otras sociedades entre ciudadanos, pequeñas e imperfectas, es verdad, pero de todos modos sociedades [entiéndase las asociaciones] $\left(\mathrm{n}^{\circ} 35\right)^{10}$.

En estos términos, la distinción entre dos formas de sociedad se funda en una visión realista de la condición humana sobre la evidente inca-

10 En adelante todas las referencias a los textos eclesiales de los pontífices están tomadas de Documentos del Magisterio Social Pontificio... En esta línea, véase J. Ma SETIEN: Iglesia y libertades políticas (Cristiandad, Madrid, 1964, 341-367). 
pacidad de cada hombre para bastarse a sí mismo fuera del marco social. Toda sociedad nace del hecho innegable de que el ser humano no es autosuficiente. A partir de este principio antropológico y social, en consecuencia, León XIII habla de la "sociedad civil" y de "otras sociedades". Mientras la primera es considerada como "grande" o macrosociedad, la cual coincide con la sociedad política; la otra, en cambio, es representada por un conjunto de "pequeñas" o microsociedades, las cuales vienen a coincidir con las asociaciones de diverso tipo (aunque especialmente los "sindicatos") que no se identifican con la comunidad política o el Estado $^{11}$.

Ahora bien, ambos tipos de sociedad, a juicio del Papa, difieren entre sí por sus "fines próximos". En efecto:

El fin establecido para la sociedad civil [entiéndase la comunidad política] alcanza a todos, en cuanto que persigue el bien común, del cual es justo que participen todos y cada uno según la proporción debida. Por esto, dicha sociedad recibe el nombre de pública, pues mediante ella se unen los hombres entre sí para constituir un pueblo (o nación). Las que se forman, por el contrario, diríamos en su seno, se consideran y son sociedades privadas [entiéndase las asociaciones], ya que su finalidad inmediata es el bien privado de sus miembros exclusivamente. 'Es sociedad privada, en cambio, la que se constituye con miras a algún negocio privado, como cuando dos o tres se asocian para comerciar unidos' (Santo Tomás, Contra impugnantes Dei cultum et religionem, c. 2) $\left(\mathrm{n}^{\circ} 35\right)$.

A tenor de estos párrafos queda en evidencia que la "sociedad civil" se identifica con la comunidad política (o el Estado), como así también que las sociedades pequeñas corresponden a las asociaciones, las cuales existen dentro o son como partes suyas (son, dicho analógicamente, como los miembros que forman el cuerpo). Así, mientras la sociedad civil (= sociedad política) es universal, pública y tiende al bien común, las otras sociedades (= asociaciones), en cambio, son particulares, privadas $y$ tienden solo al bien de aquellos que están asociados. Atendiendo a sus fines, entonces, podríamos hablar aquí de sociedad pública (Estado) y sociedades privadas (asociaciones). Mientras en la primera los individuos valoran la unión social por cuanto tiende al bien común; en la

11 Con anterioridad a los dos tipos de sociedad mencionados arriba se encuentra la familia o sociedad doméstica, "bien pequeña, es cierto, pero verdadera sociedad y más antigua que cualquiera otra” ( $\left.{ }^{\circ} 9\right)$. 
segunda, en cambio, cada persona valora su unión solo como un medio para satisfacer sus fines privados o su autointerés.

El siguiente cuadro nos ayuda a ver en síntesis y con claridad lo dicho hasta aquí:

\begin{tabular}{|c|c|}
\hline Sociedad 1 & Sociedad 2 \\
\hline Grande y perfecta & Pequeñas e imperfectas \\
\hline Pública & Privada \\
\hline Fin universal & Fin particular \\
\hline Bien común & Bien privado \\
\hline Sociedad civil & Sociedad privada \\
\hline SOCIEDAD POLÍTICA (ESTADO) & ASOCIACIONES \\
\hline
\end{tabular}

Ahora bien, en el contexto de las sociedades privadas, León XIII menciona con énfasis los sindicatos o asociaciones de obreros -uno de los aspectos fundamentales de su encíclica-, así como las variadas asociaciones, comunidades y congregaciones religiosas fomentadas por la Iglesia con una autonomía relativa respecto del Estado. Todas estas sociedades privadas -al igual que la sociedad civil-, como hemos indicado, nacen de la misma naturaleza social del hombre, por tanto, fundan su existencia en el "derecho natural". A partir de este principio, León XIII afirma que los ciudadanos poseen la libre facultad para asociarse, y al mismo tiempo tienen también el derecho a elegir libremente el reglamento y las leyes que juzguen más adecuadas para conseguir el fin que se proponen; es decir, no solo libertad de asociación, sino también libertad respecto al Estado para establecer los términos de su organización y disciplina interna.

Por último, el Papa establece la manera en que se han de relacionar la sociedad civil y las demás sociedades privadas que se desenvuelven en su seno (aunque, obviamente, sin absorberlas): 1) la sociedad civil (= sociedad política o Estado) ha sido instituida para defender, no para aniquilar, el derecho natural; 2) por tanto, de suyo y en general no tiene el Estado o la autoridad política poder para prohibir su existencia, ya que, en cuanto nacen del mismo principio, si prohibiera a los ciudadanos hacer entre sí estas asociaciones, se contradiría a sí mismo; 3) es deber del Estado, en consecuencia, proteger tales asociaciones sin entrometerse en lo íntimo de su organización ni de su disciplina, porque la acción vital procede de un principio interno; 4) sin embargo, lo anterior 
no significa que el Estado se desentienda de las asociaciones, especialmente aquellas que se oponen a las leyes, como cuando van en contra de la probidad, la justicia o el bien del Estado (o sea, el bien común). En estos casos, y con el cuidado de no violar los derechos de los ciudadanos, la autoridad pública tiene todo el derecho a impedir (o sea, a restringir la libertad) para que se formen, o también para disolver las ya formadas.

Para concluir este apartado, y sin ánimo de exhaustividad, podemos extraer algunas conclusiones preliminares a partir de la enseñanza social de León XIII. Ante todo, queda demostrado que la distinción entre dos tipos de sociedades ya se encuentra de forma explícita y bastante clara en la primera encíclica social de la Iglesia, la cual ha sido considerada con toda razón como la "Carta magna" de la doctrina social. En este sentido, creo que podemos afirmar que la Rerum novarum puede ser considerada también como la Carta magna de la sociedad civil. Ciertamente que se puede cuestionar, aunque de manera extemporánea y superflua, la identificación nominal realizada por León XIII entre "sociedad civil" y "comunidad política o Estado". Sin embargo, opino que esta dificultad desaparece si aceptamos razonablemente que al hablar de la sociedad civil el Papa no tiene en mente el uso que nosotros le concedemos en la actualidad, aunque obviamente lo anticipa. Por eso, basta romper la identificación nominal para obtener su significado contemporáneo. De este modo, podemos leer la distinción a la luz de su significado actual en los términos de la comunidad política o el Estado (sociedad 1), por un lado, dejando la expresión sociedad civil para las asociaciones religiosas y seculares (especialmente los sindicatos), por el otro (sociedad 2).

Nótese que se trata solo de proponer un cambio de nombres y la doctrina de fondo se mantiene intacta. Así, la gran mayoría de los especialistas actuales estaría de acuerdo con León XIII en que el derecho de asociación es el pilar fundamental para las diferentes asociaciones cívicas y religiosas que dan vida a la sociedad civil. Esto es obvio, ya que el Estado de derecho impone un marco legal que precisamente garantiza el ejercicio de las libertades individuales, especialmente el derecho de asociación. También estarían de acuerdo con el Papa en que no todas las asociaciones poseen fines que son beneficiosos para el bien común o el interés público, y que, por lo tanto, el Estado debe tutelar los derechos de todos los miembros de la sociedad cuando éstos se ven amenazados por sus miembros reunidos asociativamente, por ejemplo, cuando su 
asociación se funda en una ideología que promueve y emprende acciones racistas o de otro tipo semejante.

\section{JUAN PABLO II Y LOS GRUPOS INTERMEDIOS}

Al revisar la enseñanza social de Juan Pablo II -especialmente en la tríada Solicitudo rei socialis, Laborem excercens y Centesimus annus- hay que partir por afirmar que el Papa no utiliza la expresión "sociedad civil" para indicar un ámbito social relativamente autónomo del Estado ${ }^{12}$. A decir verdad, cuando usa la expresión su semántica siempre remite a la sociedad política o el Estado. Como he advertido más arriba, este significado es coherente con el uso adoptado en el magisterio social de los sumos pontífices. Con todo, y al igual que en el caso de León XIII, considero que en Juan Pablo II es posible rastrear los elementos que forman parte de una concepción católica de la sociedad civil.

Como no podía ser de otro modo, la enseñanza de Juan Pablo II parte de la Carta magna de la DSI, tal como es la Rerum novarum de León XIII. En un espíritu de evidente continuidad, en el $n^{\circ} 7$ de la Carta encíclica Centesimus annus (1-V-1991), el Papa reafirma la enseñanza de su predecesor sobre el derecho natural de asociación:

En estrecha relación con el derecho de propiedad, la encíclica de León XIII afirma también otros derechos, como propios e inalienables de la persona humana. Entre éstos destaca, dado el espacio que el Papa le dedica y la importancia que le atribuye, el 'derecho natural del hombre' a formar asociaciones privadas; lo cual significa ante todo el derecho a crear asociaciones profesionales de empresarios y obreros, o de obreros solamente. Esta es la razón por la cual la Iglesia defiende y aprueba la creación de los llamados sindicatos, no ciertamente por prejuicios ideológicos, ni tampoco por ceder a una mentalidad de clase, sino porque se trata precisamente de un 'derecho natural' del ser humano y, por consiguiente, anterior a su integración en la sociedad política. En efecto, 'el Estado no puede prohibir su formación', porque 'el Estado debe tutelar los derechos naturales, no destruirlos. Prohibiendo tales asociaciones, se contradiría a sí mismo'.

En este contexto, junto al derecho natural del hombre a formar asociaciones privadas como idea clave de León XIII, Juan Pablo II avanza en

12 Cf. J. Migliore: "Mercado, Estado y Sociedad Civil: de Centesimus annus a Caritas in veritate". Revista Cultura Económica, No 75/76 (2009), 33. 
la reflexión llamando la atención sobre otra idea que está en el centro de la propuesta contenida en la Rerum novarum, a saber, el reconocimiento de la limitación inherente al Estado para resolver por sí solo la llamada cuestión social. En palabras del Papa:

Si León XIII apela al Estado para poner un remedio justo a la condición de los pobres, lo hace también porque reconoce oportunamente que el Estado tiene la incumbencia de velar por el bien común y cuidar que todas las esferas de la vida social, sin excluir la económica, contribuyan a promoverlo, naturalmente dentro del respeto debido a la justa autonomía de cada una de ellas. Esto, sin embargo, no autoriza a pensar que según el Papa toda solución de la cuestión social deba provenir del Estado. Al contrario, él insiste varias veces sobre los necesarios límites de la intervención del Estado y sobre su carácter instrumental, ya que el individuo, la familia y la sociedad son anteriores a él y el Estado mismo existe para tutelar los derechos de aquel $\mathrm{y}$ de éstas, y no para sofocarlos (Centesimus annus, $\mathrm{n}^{\circ} 11$ ).

Esta enseñanza, a juicio del Papa, se funda en una adecuada concepción de la persona humana y de su valor único como guía de toda la trama social, no solo respecto a la comunidad política o el Estado, sino también de las múltiples formas que dan vida a los grupos sociales intermedios. En efecto,

...de la justa concepción cristiana de la persona se sigue necesariamente una justa visión de la sociedad. Según la Rerum novarum y la doctrina social de la Iglesia, la socialidad del hombre no se agota en el Estado, sino que se realiza en diversos grupos intermedios, comenzando por la familia y siguiendo por los grupos económicos, sociales, políticos y culturales, los cuales, como provienen de la misma naturaleza humana, tienen su propia autonomía, sin salirse del ámbito del bien común (Centesimus annus, $\left.\mathrm{n}^{\circ} 13\right)$.

Es importante resaltar aquí que desde el punto de vista de su fundamento los llamados grupos intermedios no son únicamente la expresión de la misma condición natural humana que tiende a la vida social -un principio vital interno que se ajusta a la conocida expresión aristotélica del politikón zóion-, sino que también incluye una comprensión moderna que se manifiesta como el despliegue de la subjetividad individual. En palabras de Juan Pablo II, los diferentes grupos intermedios son la expresión de "la subjetividad del hombre en la vida social" (Laborem exercens (14-IX-1981), n 14); o bien, en palabras aún más precisas, son 
el fruto de "la subjetividad creativa del ciudadano" (Sollicitudo rei socialis (30-XII-1987), $\left.\mathrm{n}^{\circ} 15\right)$.

El reconocimiento de la subjetividad como una dimensión creativa de la vida social es sumamente relevante, ya que nos permite comprender la sociedad civil como la expresión más importante del proceso mismo de socialización - un fenómeno ya advertido por Juan XXIII en su encíclica Mater et magistra (15-V-1961) ${ }^{13}-$, el cual puede entenderse como un incremento de nuevas formas de vida asociada, una multitud de iniciativas privadas, grupos o cuerpos intermedios que poseen una variedad de finalidades económicas, sociales, culturales, profesionales, políticas, etc. Estos grupos han de gozar de una autonomía efectiva respecto a los poderes públicos, en la medida que mantengan su subordinación a las exigencias del bien común y donde cada uno de sus miembros sea considerado y tratado como persona (Laborem exercens, $\mathrm{n}^{\circ} 14$ ).

Ahora bien, los grupos sociales intermedios (o asociaciones) que nacen de la libre voluntad de los ciudadanos, van diferenciándose según la variedad de ámbitos de la actividad humana. Como hemos dicho, esto se manifiesta en el creciente proceso de socialización que da paso a nuevas formas de vida sociales, políticas, económicas, culturales, profesionales, etc. A pesar de esta amplitud en el reconocimiento de la pluralidad social, hay que admitir que en la trayectoria histórica de la DSI las asociaciones de los trabajadores -es decir, los sindicatos- que se dan cita en el ámbito de las relaciones económicas y productivas, han concentrado una especial preocupación entre los pontífices. En este punto es importante aclarar que la configuración de lo que llamamos sociedad civil en la trayectoria histórica del pensamiento social católico $-\mathrm{y}$ que puede caracterizarse muy bien siguiendo una línea de pensamiento que parte

13 Efectivamente, en los números 59 al 67 de su encíclica, Juan XXIII expone su definición, naturaleza y causas de la socialización. En este sentido, habla sobre "el incremento de las relaciones sociales, o sea, la progresiva multiplicación de las relaciones de convivencia, con la formación consiguiente de muchas formas de vida y de actividad asociada, que han sido recogidas, la mayoría de las veces, por el derecho público o por el derecho privado" (no 59). "Esta tendencia ha suscitado por doquiera, sobre todo en los últimos años, una serie numerosa de grupos, de asociaciones y de instituciones para fines económicos, sociales, culturales, recreativos, deportivos, profesionales y políticos, tanto dentro de cada una de las naciones como en el plano mundial" ( ${ }^{\circ}$ 60). En esta misma línea, véase Concilio Vaticano II, Constitución Gaudium et spes, n 25. 
de la persona como centro de la sociedad y que va abriéndose paulatinamente a las múltiples formas de vida asociada-, siempre se desenvuelve como un proceso de distinción respecto a la comunidad política o el Estado $^{14}$. En este sentido, los sindicatos son entendidos precisamente como una forma de vida asociada con fines éticos que responde a una lógica de acción que nace del reconocimiento de la dignidad humana, tal como pone de manifiesto Juan Pablo II al hablar de la primacía de la subjetividad del hombre en la vida social y especialmente en la estructura dinámica de todo el proceso económico.

Aunque más adelante hablaremos sobre la propuesta de Benedicto XVI, aquí conviene adelantar que en el $\mathrm{n}^{\circ} 38$ de la encíclica Caritas in veritate (29-VI-2009) el Papa sostiene que su predecesor Juan Pablo II advierte sobre "la necesidad de un sistema basado en tres instancias: el mercado, el Estado y la sociedad civil”. Afirma, además, que la sociedad civil -según el mismo Juan Pablo II- es "el ámbito más apropiado para una economía de la gratuidad y de la fraternidad, sin negarla en los otros dos ámbitos”. Pues bien, ¿es esto así? A continuación intentaré responder a esta pregunta.

Tal como está indicado en la respectiva nota a pie de página de su encíclica, Benedicto XVI apoya su interpretación en el $n^{\circ} 35$ de la encíclica Centesimus annus. Sin embargo, para entender correctamente ese número es necesario detenerse antes en $\mathrm{el} \mathrm{n}^{\circ} 34$, el cual se refiere al libre mercado.

Según Juan Pablo II, la impresión que se tiene sobre el libre mercado consiste en que representa el instrumento más eficaz para colocar los recursos y responder eficazmente a las necesidades humanas. Con el fin de aclarar esta impresión, el Papa distingue entre dos órdenes diferentes de necesidades: el primer orden coincide con aquellas necesidades que son solventables y vendibles -las cuales se relacionan respectivamente con el poder adquisitivo y con el precio- y que ciertamente son válidas en el mercado; el segundo orden, en cambio, se refiere a las numerosas necesidades humanas que no tienen salida en el mercado, ya que no tienen relación con el poder adquisitivo ni pueden tener un precio. A este tenor, la satisfacción del primer orden de necesidades depende de la lógica de los intercambios

14 Sobre el proceso secular de distinción entre sociedad política o Estado y lo que llamamos sociedad civil puede verse el excelente trabajo de N. Boвbio: Estado, Gobierno y Sociedad..., 39-67. 
que es propia del mercado, mientras que satisfacer el segundo orden de necesidades es un estricto deber de justicia y de verdad. Por tanto, concluye Juan Pablo II: "Por encima de la lógica de los intercambios a base de los parámetros y de sus formas justas, existe algo que es debido al hombre porque es hombre, en virtud de su eminente dignidad". En este sentido, podemos hablar de la primacía de la lógica de la dignidad humana, una lógica de la acción que pone a la persona humana como principio, sujeto y fin de todas las instituciones sociales.

Dicho lo anterior, Juan Pablo II continúa en el $n^{\circ} 35$-citado por Benedicto XVI- afirmando que los objetivos de la Rerum novarum todavía representan una meta pendiente que abre "un vasto y fecundo campo de acción y de lucha" que está en contra de un sistema económico que ensalza el predominio absoluto del capital, la posesión de los medios de producción y la tierra, el cual sofoca la libre subjetividad del trabajo del hombre. En este contexto, Juan Pablo II advierte sobre la necesidad de una sociedad basada en el trabajo libre, en la empresa y en la participación. Precisamente, aquí intervienen los sindicatos y demás organizaciones de los trabajadores (que, en nombre de la justicia, defienden sus derechos y tutelan su persona, desempeñando al mismo tiempo una función social de carácter cultural, para hacerles participar de manera más plena y digna en la vida de la Nación y ayudarles en la vida del desarrollo), así como también la empresa (entendida como una comunidad de hombres cuya finalidad no es simplemente la producción de beneficios). Como tal, añade Juan Pablo II, la sociedad así definida, no se opone al mercado, sino que exige que éste sea controlado oportunamente por las fuerzas sociales y por el Estado, de manera que se garantice la satisfacción de las exigencias fundamentales de toda la sociedad. Así, el cuadro queda de la manera siguiente:

\begin{tabular}{|c|c|c|}
\hline Estado & $\begin{array}{c}\text { Sistema económico } \\
\text { Libre mercado } \\
\text { (predominio absoluto } \\
\text { del capital, la posesión } \\
\text { de los medios de } \\
\text { producción y la tierra) }\end{array}$ & $\begin{array}{c}\text { Sociedad basada en } \\
\text { el trabajo libre, en } \\
\text { la empresa y en la } \\
\text { participación }\end{array}$ \\
\hline Poder político & Control & Fuerzas sociales \\
\hline
\end{tabular}


A juicio de Juan Pablo II, el Estado (poder político) y las fuerzas sociales (los sindicatos y demás organizaciones de los trabajadores que, podríamos añadir, forman parte de la sociedad civil) cumplen una función de control oportuno sobre el mercado, de manera que se garantice la satisfacción de las exigencias fundamentales de toda la sociedad. Y la empresa, por su parte, es integrada en esa sociedad solo en cuanto es entendida "como comunidad de hombres que, de diversas maneras, buscan la satisfacción de sus necesidades fundamentales y constituyen un grupo particular al servicio de la sociedad entera".

En el contexto de la empresa, Juan Pablo II señala que la Iglesia reconoce "la justa función de los beneficios, como índice de la buena marcha de la empresa. Cuando la empresa da beneficios significa que los factores productivos han sido utilizados adecuadamente y que las correspondientes necesidades humanas han sido satisfechas debidamente". Sin embargo, el Papa advierte de inmediato que los "beneficios son un elemento regulador de la vida de la empresa, pero no el único; junto con ellos hay que considerar otros factores humanos y morales que, a largo plazo, son por lo menos igualmente esenciales para la vida de la empresa". Y, en efecto, es "posible que los balances económicos sean correctos y que al mismo tiempo los hombres, que constituyen el patrimonio más valioso de la empresa, sean humillados y ofendidos en su dignidad". Esto no solo es moralmente inadmisible, sino que además puede traer consigo un balance negativo para "la eficiencia económica de la empresa". En estos términos, podríamos sostener que la lógica de la dignidad humana fundamenta la actividad económica de la empresa en orden a la satisfacción de las necesidades humanas fundamentales y al mismo tiempo promueve la participación del trabajador en relación al bien común de la sociedad. De este modo, y siguiendo estrictamente lo dicho por el Papa, el capitalismo es aceptable solo si se entiende como "un sistema económico que reconoce el papel fundamental y positivo de la empresa, del mercado, de la propiedad privada y de la consiguiente responsabilidad para con los medios de producción, de la libre creatividad humana en el sector de la economía” (CA, $\mathrm{n}^{\circ} 42$ ). En este capitalismo, el cual sería mejor llamar, a juicio de Juan Pablo II, como "economía de empresa", "economía de mercado", o simplemente como "economía libre", ha de quedar siempre asegurada la libertad en el ámbito económico, aunque encuadrada en un sólido contexto jurídico impuesto por el Estado que 
pone dicha libertad al servicio de la libertad humana integral y cuyo centro es ético y religioso (CA, $\mathrm{n}^{\circ} 42$ ).

Ahora bien, volviendo a la cuestión planteada al inicio: ¿enseña Juan Pablo II la distinción entre tres instancias (mercado, Estado y sociedad civil) en el número 35 de Centesimus annus? Creo que la respuesta se obtiene en el contexto más amplio de la encíclica. Según el diagnóstico de Juan Pablo II, “[e]l individuo hoy día queda sofocado con frecuencia entre los dos polos del Estado y del mercado. En efecto, da la impresión a veces de que existe solo como productor y consumidor de mercancías, o bien como objeto de la administración del Estado, mientras se olvida que la convivencia entre los hombres no tiene como fin ni el mercado ni el Estado, ya que posee en sí misma un valor singular a cuyo servicio deben estar el Estado y el mercado" ( $\left.\mathrm{n}^{\circ} 49\right)$. Tal como interpreto el planteamiento de Juan Pablo II, la noción de la sociedad civil surge a partir de la misma concepción de la naturaleza social de la persona y su dignidad. En este sentido, se puede sostener que la sociedad civil aparece estrechamente unida a una visión de la persona (en clara sintonía con lo que he llamado la lógica de la dignidad humana).

Por otra parte, en la misma encíclica, Juan Pablo II afirma en el $\mathrm{n}^{\circ}$ 43, que para superar la mentalidad individualista (podríamos pensar en aquella que promueven las formas extremas del liberalismo político y económico, el libertarismo o neoliberalismo), "se requiere un compromiso de solidaridad y caridad, que comienza dentro de la familia con la mutua ayuda de los esposos y, luego, con las atenciones que las generaciones se prestan entre sí. De este modo la familia se cualifica como comunidad de trabajo y de solidaridad". "Además de la familia-continúa el Papa-, desarrollan también funciones primarias y ponen en marcha estructuras de solidaridad otras sociedades intermedias. Efectivamente, éstas maduran como verdaderas comunidades de personas y refuerzan el tejido social, impidiendo que caiga en el anonimato y en la masificación impersonal, bastante frecuente por desgracia en la sociedad moderna. En medio de esa múltiple interacción de las relaciones vive la persona y crece la 'subjetividad de la sociedad'".

De este modo, el esquema final de la visión de Juan Pablo II sobre la sociedad civil queda establecido del siguiente modo: 


\begin{tabular}{|c|c|c|}
\hline Estado & Sociedad Civil & Mercado \\
\hline $\begin{array}{c}\text { Gobierno } \\
\text { como aparato } \\
\text { administrativo y } \\
\text { marco jurídico }\end{array}$ & $\begin{array}{l}\text { La familia y sociedades } \\
\text { o grupos intermedios } \\
\text { de carácter social, } \\
\text { económico, político, } \\
\text { cultural, religioso, etc. }\end{array}$ & $\begin{array}{l}\text { Sistema económico } \\
\text { (economía de } \\
\text { empresa, economía de } \\
\text { mercado o economía } \\
\text { libre) }\end{array}$ \\
\hline $\begin{array}{c}\text { Ciudadanía } \\
\text { (derechos y deberes) }\end{array}$ & $\begin{array}{c}\text { Dignidad de la } \\
\text { persona } \\
\text { (subjetividad de la } \\
\text { persona y subjetividad } \\
\text { de la sociedad) } \\
\end{array}$ & $\begin{array}{l}\text { Productor y } \\
\text { consumidor }\end{array}$ \\
\hline $\begin{array}{l}\text { Lógica del poder } \\
\text { político y coercitivo }\end{array}$ & $\begin{array}{c}\text { Lógica de la } \\
\text { solidaridad y la } \\
\text { caridad }\end{array}$ & $\begin{array}{l}\text { Lógica del } \\
\text { intercambio y del } \\
\text { contrato }\end{array}$ \\
\hline
\end{tabular}

En este contexto, el bien de la persona humana y de la sociedad, ese que se configura según su propia dignidad, solo se edifica y es posible sobre la base de la persona como sujeto autónomo de decisión moral, como responsabilidad asumida, única y exclusiva, ante el bien y el mal (cf. CA, n ${ }^{13}$ ). Así, "la primera y más importante labor -en palabras de Juan Pablo II- se realiza en el corazón del hombre, y el modo como éste se compromete a construir el propio futuro depende de la concepción que tiene de sí mismo y de su destino" (CA, n 51).

\section{BENEDICTO XVI Y LA SOCIEDAD CIVIL}

Con toda seguridad podemos considerar a Benedicto XVI como el Papa de la sociedad civil. De hecho, es él quien por primera vez utiliza explícitamente la expresión para significar un ámbito distinto de la sociedad política o el Estado. En efecto, ya en su primera encíclica Deus caritas est (25-XII-2005) realiza una breve mención cuando sostiene que "la solidaridad expresada por la sociedad civil supera de manera notable a la realizada por las personas individualmente" $\left(n^{\circ} 30 a\right)^{15}$. En estos términos, la sociedad civil es entendida como el ámbito propio de la soli-

15 Véase un breve comentario en A. EsPINA: "La organización de la caridad en la encíclica Deus caritas est", Revista Valores en la Sociedad Industrial, No 66 (2006), 41-44. 
daridad organizada en múltiples estructuras de servicio tanto religiosas como civiles. En ella se dan cita un sinnúmero de entidades eclesiales, las múltiples organizaciones con objetivos caritativos o filantrópicos y las muchas formas de voluntariado $\left(\mathrm{n}^{\circ} 30 \mathrm{~b}\right)^{16}$.

En este contexto, a juicio del Papa, el Estado constituye el órgano encargado de velar y coordinar todas las iniciativas que se implementan en la sociedad civil en vistas a la realización del bien común. En sus propias palabras: "Lo que hace falta no es un Estado que regule y domine todo, sino que generosamente reconozca y apoye, de acuerdo con el principio de subsidiaridad, las iniciativas que surgen de las diversas fuerzas sociales y que unen la espontaneidad con la cercanía a los hombres necesitados de auxilio. La Iglesia es una de estas fuerzas vivas: en ella late el dinamismo del amor suscitado por el Espíritu de Cristo» (n 28b).

La actividad de las organizaciones caritativas de la Iglesia, por tanto, pertenece al ámbito de la sociedad civil, y han de ser independientes de partidos e ideologías: "No es un medio para transformar el mundo de manera ideológica y no está al servicio de estrategias mundanas, sino que es la actualización aquí y ahora del amor que el hombre siempre necesita" ( $\left.\mathrm{n}^{\circ} 31 \mathrm{~b}\right)$.

En esta línea de ideas, Benedicto XVI continúa sus reflexiones en la encíclica Caritas in veritate, aunque esta vez en el ámbito de la economía internacional ${ }^{17}$. A su juicio, la economía global parece privilegiar de manera exclusiva la lógica del intercambio contractual, sin embargo, sus propias insuficiencias demuestran que necesita de la lógica de la política (el Estado) y la lógica del don (la sociedad civil). "Indudablemente -afirma el Pontífice-, la vida económica tiene necesidad del contrato para regular las relaciones de intercambio entre valores equivalentes. Pero necesita igualmente leyes justas y formas de redistribución guiadas por la política, además de obras caracterizadas por el espíritu del don. La economía globalizada parece privilegiar la primera lógica, la del intercambio contrac-

16 En esta línea puede leerse la enseñanza de Juan Pablo II sobre las formas agregativas de participación en la vida de la Iglesia. Véase, Exhortación apostólica Christifideles Laici (30-XII-1988), no 29.

17 Al respecto, véase los trabajos de J. Migliore: "Mercado, Estado y Sociedad Civil: de Centesimus annus a Caritas in veritate"... y A. GALIndo: "La lógica del don en el horizonte de la sociedad civil". Veritas, 28 (2013), 9-40. 
tual, pero directa o indirectamente demuestra que necesita a las otras dos, la lógica de la política y la lógica del don sin contrapartida" ( $\left.n^{\circ} 37\right)$.

Lo propio de la sociedad civil, entonces, es lo que el Papa llama la lógica de la gratuidad. A través de esta lógica se fomenta la solidaridad, la reciprocidad fraterna y la responsabilidad por la justicia y el bien común en sus diversas instancias y agentes $\left(\mathrm{n}^{\circ} 38\right)$. En este contexto, pensar exclusivamente en el binomio mercado-Estado "corroe la sociabilidad, mientras que las formas de economía solidaria, que encuentran su mejor terreno en la sociedad civil aunque no se reducen a ella, crean sociabilidad. El mercado de la gratuidad no existe y las actitudes gratuitas no se pueden prescribir por ley. Sin embargo, tanto el mercado como la política tienen necesidad de personas abiertas al don recíproco" $\left(\mathrm{n}^{\circ} 39\right)$.

Así, el cuadro sería el siguiente:

\begin{tabular}{|c|c|c|}
\hline Estado & Mercado & Sociedad Civil \\
\hline Lógica de la política & $\begin{array}{c}\text { Lógica del intercambio } \\
\text { contractual }\end{array}$ & Lógica del don \\
Poder & Riqueza & Solidaridad \\
Leyes justas y formas & $\begin{array}{c}\text { Relaciones de intercambio } \\
\text { entre valores equivalentes }\end{array}$ & $\begin{array}{c}\text { Principio de gratuidad } \\
\text { ye la fraternidad } \\
\text { Dar por deber }\end{array}$ \\
\hline Dar para tener & Dar por don \\
\hline
\end{tabular}

Desde esta perspectiva, según Benedicto XVI, la lógica del mercado y la lógica del Estado no pueden prescindir de la gratuidad, ya que a la larga se debilita la solidaridad en las relaciones entre los ciudadanos, la participación y el sentido de pertenencia. En contrapartida, la lógica del don "fomenta y extiende la solidaridad y la responsabilidad por la justicia y el bien común en sus diversas instancias y agentes" ( $\left.n^{\circ} 38\right)$. La lógica de la solidaridad que es la propia de la sociedad civil, en definitiva, quiere significar un tipo de sociabilidad por el que todos se sientan responsables de todos. Y esto, a su vez, significa tener en el mercado y en el Estado personas abiertas al don recíproco $\left(\mathrm{n}^{\circ} 39\right)$.

\section{CONCLUSIÓN}

Al terminar esta breve exposición es necesario recordar la pregunta formulada al inicio: ¡existe un fundamento doctrinal que justifique el nuevo 
significado de la sociedad civil como distinto de la comunidad política? En el Compendio se afirma que la Iglesia "ha contribuido a establecer la distinción entre comunidad política y sociedad civil, sobre todo con su visión del hombre, entendido como ser autónomo, relacional, abierto a la Trascendencia" (no 417). Aunque no se ofrece ninguna justificación que avale esta afirmación, hay que reconocer que después recorrer brevemente la enseñanza social de León XIII, Juan Pablo II y Benedicto XVI, podemos afirmar que efectivamente hay razones profundas para estar de acuerdo. La persona concebida como un ser intrínsecamente social, el derecho de asociación (junto a otros derechos fundamentales de la persona) que permite el desenvolvimiento de la subjetividad creativa del ciudadano, la sociabilidad que se realiza fuera del Estado y que da vida a una multitud de formas de vida asociada o cuerpos sociales intermedios que colaboran en la realización del bien común, la lógica de la gratuidad que se deriva del compromiso solidario con el prójimo como factor de desarrollo personal y social, son algunas de las ideas que abonan en la enseñanza social católica una concepción de la sociedad civil como distinta de la sociedad política o el Estado. En esta línea, y para terminar, la sociedad civil no es anti-Estado - ni tampoco antimercado- sino que se presenta como un auténtico proyecto ético en el que la persona humana y su inalienable dignidad es el principio, el sujeto y el fin de todas las instituciones sociales. 